\title{
Technological practicability of the numerical modeling of induction heating process in steel pieces ${ }^{(\bullet)}$
}

\author{
A. Iagar ${ }^{*}$, I. Sora ${ }^{* *}$, D. Radu**, C. Panoiu* and C. Abrudean ${ }^{*}$
}

\begin{abstract}
This paper presents the numerical modeling (using the Finite Difference Method-FDM, and Finite Element MethodFEM) of the electromagnetic and thermal fields in a steel piece heated up inside an induction crucible furnace, and the experimental validations. Both modelings have been validated experimentally, so they can be used in designing the equipments and in the numerical control of induction heating process. The program based on FDM can be used in the first stage of designing due to the reduced CPU time. In this stage the inductor parameters and heating time can be estimated, and a study of the influence of diverse factors upon the heating process can be achieved. The FLUX 2D program can be used in the optimization stage, because it allows a more thorough analysis of the phenomena.
\end{abstract}

\section{La utilidad tecnológica del modelado numérico en el calentamiento por inducción de las piezas de acero}

\begin{abstract}
Resumen
El trabajo presenta el modelado numérico (con el Método de la Diferencias Finitas-FDM y el Método de los Elementos Finitos-FEM), de los campos electromagnéticos y térmicos de una pieza de acero calentada en un horno de inducción con crisol y las validaciones experimentales. Los dos modelados siendo válidos desde el punto de vista experimental, se pueden utilizar para la proyección de unos equipos y por el control numérico del proceso de calentamiento por inducción. El programa basado en FDM se puede utilizar en la primera etapa de la proyección, gracias al tiempo corto de rodadura. En esta etapa se pueden estimar los parámetros del inductor, el tiempo de calentamiento y se puede realizar un estudio de la influencia que tienen los distintos factores sobre el proceso de calentamiento. El programa FLUX 2D se puede utilizar en la etapa de optimización, porque permite un análisis más detallado de los fenómenos.
\end{abstract}

Palabras clave

\section{INTRODUCTION}

Induction heating is used more and more in the industry, due to the advantages offered comparatively with other heating methods for metallic materials (the non-polluting nature of the technological processes, high heating speed, special quality of the products, and accurate control of the technological processes) $)^{[1,2 \text { and } 3] \text {. }}$

This article joints the current international research effort concerning the promotion of modern modeling and control methods in the induction heating electrotechnology.
In the last years, one of the goals of research in the induction heating domain has been the development of numerical modelings for the computation of the electromagnetic and thermal fields (in linear or non-linear media), either in static regime or taking into account the motion, mechanical stress and the phase transitions ${ }^{[4-11]}$.

Among the numerical methods which have been used we mention: Finite Difference Method (FDM), Finite Element Method (FEM), Boundary Element Method (BEM) and Volume Integral Method (VIM) [12]. The mixed methods (i.e. FEM-BEM) are interesting due to their ability to take into account

(•) Trabajo recibido el día 2 de julio de 2007 y aceptado en su forma final el día 27 de julio de 2008.

* Faculty of Engineering Hunedoara, Politechnica University of Timisoara, 5 Revolutiei Street, Hunedoara 331128, Romania.

${ }^{* *}$ Faculty of Electrical Engineering, Politechnica University of Timisoara, 2 Vasile Parvan Bd, Timisoara 300223, Romania, E-mail: angela.iagar@fih.upt.ro. 
open domains and inductor displacements ${ }^{[4,13}$ and 14]. The FEM approach has been preferred since it involves sparse matrices, that leads to reductions in terms of CPU time and memory requirements, and is more suited for parallel computing ${ }^{[6,15}$ and 16].

In order to reduce the time of computation and to improve the accuracy, numerical modelings for the optimization of the induction heating processes have also been developed ${ }^{[6}$ and 17-24] . These modelings aim to establish the parameters of the inductor and/or frequency and the supplying voltage, in such way as to satisfy the technological requirements with a minimal power supply and a minimal heating time.

For the optimal control of the induction heating process, the modeling programs (i.e. FLUX) may be coupled for a co-simulation with other packages, dedicated to the electric circuits (i.e., Simulink) [25].

This allows for the implementation of some complex control laws and regulation loops, also maintaining a very high accuracy of the magnetic and thermal fields computation.

The present paper has as objectives the development of numerical modelings for the inductive heating process in steel pieces, and their experimental validation, in order to be used in the designing of equipments and in the control of induction heating process.

The paper is organized as follows. Section 2 is dedicated to numerical modelings (using FDM and FEM) of the electromagnetic and thermal fields in a steel piece heated up inside an induction crucible furnace. Section 3 shows the experimental validations of the modelings. Section 4 is dedicated to conclusions and shows the technological practicability of these numerical modelings.

\section{THE NUMERICAL MODELING OF THE ELECTROMAGNETIC AND THERMAL FIELDS WITHIN A STEEL PIECE}

\subsection{Physical model}

The experimental setup used for studying is an induction crucible furnace, type ICI 100/2,5-PR (Fig. 1). The furnace was supplied from a medium frequency rotary generator type GEF-AV 125/2500. The inductor, 1 , has 10 turns and is made of a copper tube with the outer diameter of $38 \mathrm{~mm}$. Outside the quartzite crucible, 3 , there is an asbestos cylinder 5 ; in order to limit the thermal losses, the furnace is provided with a cover, 4 .

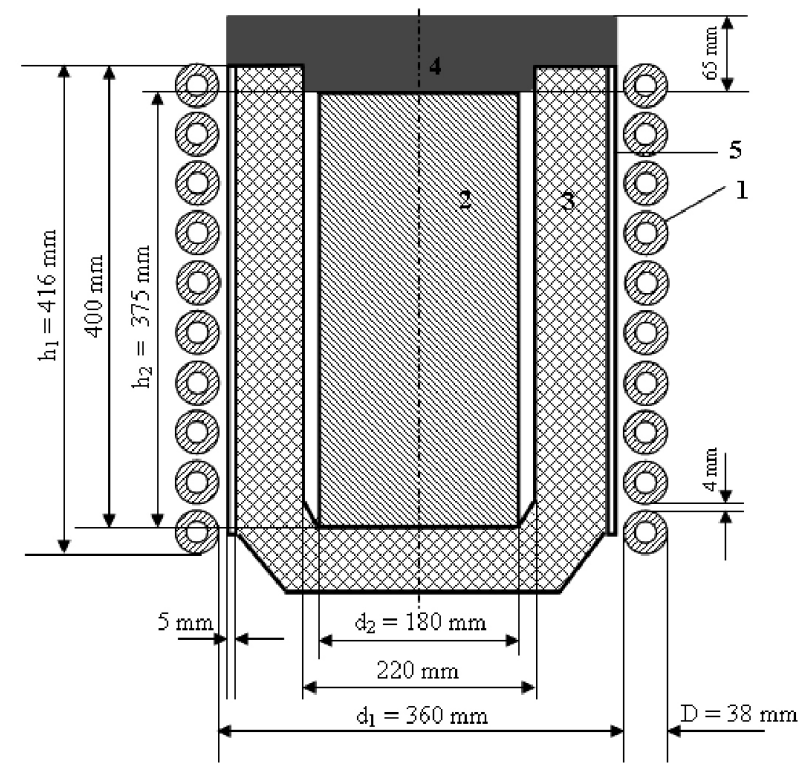

Figure 1. Position of the steel piece inside the induction furnace.

Figura 1. Colocación de la pieza de acero en el horno de inducción.

We analyzed the heating up of a cylindrical $1 \mathrm{C}$ 45,2 , steel piece, with the diameter $d_{2}=180 \mathrm{~mm}$ and height $h_{2}=375 \mathrm{~mm}$, while the inductor was being fed with a constant current ( $I=1810$ A r.m.s., $f=2500 \mathrm{~Hz}$ ).

To measure the temperature inside the steel piece, we drilled 8 longitudinal holes (Fig. 2), and placed

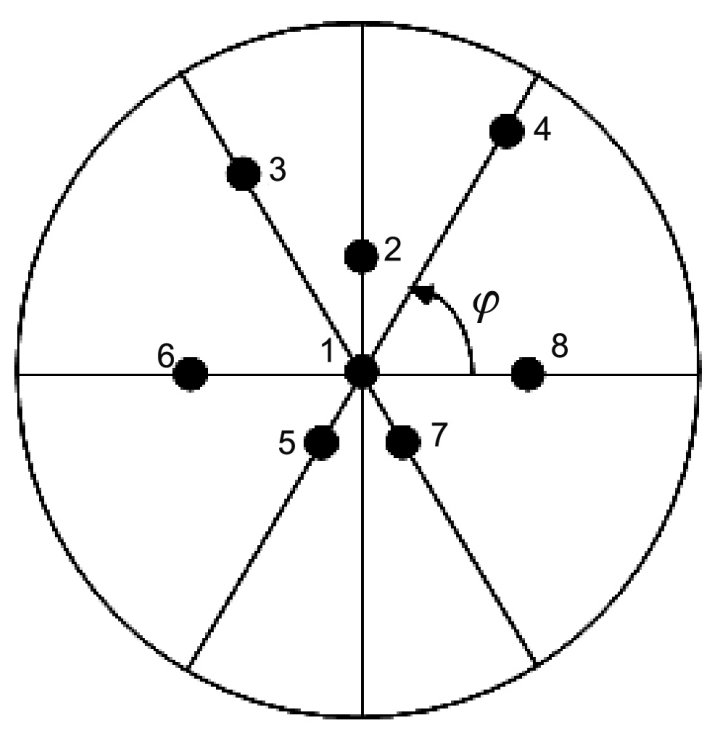

Figure 2. Position of holes for the thermocouples.

Figura 2. Posiciones de los agujeros para termoacoplamiento. 
in each of them a chromel-alumel thermocouple. The holes were drilled at the following cylindrical coordinates $(r, \varphi, z)$ :
(1) $r=0, \varphi=0, z=37 \mathrm{~mm}$
(2) $r=30 \mathrm{~mm}, \varphi=\pi / 2 \mathrm{rad}, z=37 \mathrm{~mm}$;
(3) $r=60 \mathrm{~mm}, \varphi=2 \pi / 3 \mathrm{rad}, z=37 \mathrm{~mm}$;
(4) $r=75 \mathrm{~mm}, \varphi=\pi / 3 \mathrm{rad}, z=37 \mathrm{~mm}$;
(5) $r=18 \mathrm{~mm}, \varphi=4 \pi / 3 \mathrm{rad}, z=87 \mathrm{~mm}$;
(6) $r=45 \mathrm{~mm}, \varphi=\pi \mathrm{rad}, z=87 \mathrm{~mm}$;
(7) $r=18 \mathrm{~mm}, \varphi=5 \pi / 3 \mathrm{rad}, z=107 \mathrm{~mm}$;
(8) $r=45 \mathrm{~mm}, \varphi=0, z=107 \mathrm{~mm}$,

where $z=0$ corresponds to $h_{2} / 2$.

For data acquisition we used ADAM-4018 and ADAM-4520 modules $^{[26]}$, designed for temperature measurements.

\subsection{General study hypotheses}

Within the study the following physical aspects were taken into account:

- The induction heating of ferromagnetic materials involves complex and strongly coupled phenomena (generating eddy currents, heat transfer, phase transitions and mechanical stress of the processed material);

- The electromagnetic properties (the resistivity and the magnetic permeability) and those thermal properties (the thermal conductivity and the specific heat) of ferromagnetic steel depend on temperature; moreover, near to the Curie point, the relative magnetic permeability of the steel is recording very fast variation (against temperature); these aspects could lead to troubles concerning the convergence of iterations;

- In the case of interest, the magnetic flux density is not high, the material is not saturated, thus it is possible to use the harmonic approximation (assuming that all electromagnetic fields are sine waves when the input current is a sine wave);

- The variation rate of the electromagnetic phenomena is very different comparatively to the thermal phenomena (the thermal phenomena are with few orders of magnitude slower than the electromagnetic phenomena).

As a consequence, the electromagnetic phenomena were simulated through series of sinusoidal states (permanently) within a homogeneous material, of which properties vary slowly during the time (because of the heating).

The computation of the magnetic field quantities at a given time was performed with the values of the thermal field computed at a previous moment (in the hypothesis that at a sufficiently small time step, the temperature is constant within a layer of the domain was considered).

The magnetic non-linearity of the steel piece imposed more iterations for computing the intensity of magnetic field at a certain time step.

In the thermal computation, the mean power developed by Joule effect within the processed material was used (at the respective time moment).

The study of the electromagnetic and thermal coupled fields in the ferromagnetic steel piece has been done using the following hypotheses:

- The displacement currents are small enough to be neglected;

- The phenomenon of magnetic hysteresis is neglected;

- There are no internal electrical field sources and no permanent magnetization;

- The state is considered to be sinusoidal (harmonic), thus the complex representation can be used;

- The ending effect is neglected;

- The thermal losses through the furnace cover and hearth are neglected;

- The domain under consideration is axisymmetric;

- The materials are isotropic;

- The electric conductivity of the piece, the thermal conductivity and the specific heat depend on temperature (and implicitly, on the space and time coordinates), and its magnetic permeability depends upon the intensity of magnetic field generated by the inductor, respectively on temperature (and, implicitly, on the space and time coordinates).

\subsection{The mathematical model of the electromagnetic field, coupled with the thermal field}

The electromagnetic field, generated by the inductor in the steel piece, can be determined according to Maxwell's equations for quasi-stationary state in fixed bodies. The thermal field within the steel piece can be described by Fourier's equation (supposing there are no phase transitions and the thermal transfer is made by conduction $)^{[1]}$ : 
TECHNOLOGICAL PRACTICABILITY OF THE NUMERICAL MODELING OF INDUCTION HEATING PROCESS IN STEEL PIECES LA UTILIDAD TECNOLÓGICA DEL MODELADO NUMÉRICO EN EL CALENTAMIENTO POR INDUCCIÓN DE LAS PIEZAS DE ACERO

$$
\begin{aligned}
& \operatorname{curl}(\operatorname{curl} \overrightarrow{\mathrm{H}})=\frac{1}{\sigma} \operatorname{grad} \sigma \times \operatorname{curl} \overrightarrow{\mathrm{H}}-\sigma \frac{\partial}{\partial \mathrm{t}}(\mu \overrightarrow{\mathrm{H}}) \\
& \gamma \mathrm{c} \frac{\partial \mathrm{T}}{\partial \mathrm{t}}+\operatorname{div}(-\lambda \operatorname{grad} \mathrm{T})=\mathrm{p}
\end{aligned}
$$

In equation $(1): \vec{H}[\mathrm{~A} / \mathrm{m}]$ is the intensity of magnetic field vector; $\lambda\left[\mathrm{W} / \mathrm{m}{ }^{\circ} \mathrm{C}\right], \sigma[\mathrm{ohm} \cdot \mathrm{m}]^{-1}-$ the thermal, respectively electric conductivity, of the material to be processed; $\mu[\mathrm{H} / \mathrm{m}]$ - the magnetic permeability of the material; $\gamma\left[\mathrm{kg} / \mathrm{m}^{3}\right], c\left[\mathrm{~J} / \mathrm{kg}{ }^{\circ} \mathrm{C}\right]-$ the density and the specific heat of the material to be processed; $p\left[\mathrm{~W} / \mathrm{m}^{3}\right]$ - the volume density of the power dissipated through the eddy currents induced in the steel piece; $T\left[{ }^{\circ} \mathrm{C}\right]$ - the temperature inside the processed material.

The system of equations (1) admits a unique solution under the following conditions:

- at $t=0$ we know, $T(0, P), H(O, P)$, for any point $P$ in the analyzed domain;

— the boundary conditions are known (see 2.4.1 and 2.5.2);

- the dependences $\sigma=\sigma(T)$ and $\mu_{r}=\mu_{r}(H, T)$ $[1$ and 27$]$ are known for the processed material.

\subsection{The numerical modeling of the electromagnetic and thermal fields within a steel piece using FDM}

The electromagnetic field produced by the inductor in the steel piece is determined based on the first equation from system (1).

The steel piece is axisymmetric. Neglecting the ending effect and assuming that the material of the piece is homogeneous and isotropic, and the magnetic field on the surface of the steel piece is uniform, it can be approximated that all the local quantities of the electromagnetic field from the steel piece depend only by coordinate $r$ (radius) and time $t: H=H(r, t)$, $E=E(r, t), J=J(r, t)$. Also: $\sigma=\sigma(T)=\sigma(T(r, t))$ and $\mu=\mu(\mathrm{H}, \mathrm{T})=\mu(r, t)$.

For the harmonical regime (permanently sinusoidal) the local quantities of electromagnetic field can be expressed using the simplified complex, and the previous relation (in the cylindrical coordinates) becomes ${ }^{[27}$ and 28$]$ :

$$
\frac{\mathrm{d}^{2} \underline{\mathrm{H}}}{\mathrm{dr}^{2}}+\frac{1}{\mathrm{r}} \frac{\mathrm{d} \underline{\mathrm{H}}}{\mathrm{dr}}=\frac{1}{\sigma} \frac{\mathrm{d} \sigma}{\mathrm{dr}} \frac{\mathrm{d} \underline{\mathrm{H}}}{\mathrm{dr}}+\sigma \frac{\partial \mu}{\partial \mathrm{t}} \underline{\mathrm{H}}+\mathrm{j} \omega \mu \sigma \underline{\mathrm{H}}
$$

The thermal field from the steel piece will be described by the Fourier equation (the second relation from system 1) in the cylindrical coordinates ${ }^{[27}$ and 28$]$ :

$$
\frac{\partial^{2} \mathrm{~T}}{\partial \mathrm{r}^{2}}+\frac{1}{\mathrm{r}} \frac{\partial \mathrm{T}}{\partial \mathrm{r}}+\frac{1}{\lambda} \frac{\partial \lambda}{\partial \mathrm{r}} \frac{\partial \mathrm{T}}{\partial \mathrm{r}}+\frac{\mathrm{p}}{\lambda}=\frac{\gamma \mathrm{c}}{\lambda} \frac{\partial \mathrm{T}}{\partial \mathrm{t}}
$$

The density of the eddy currents induced in the steel piece and the volume density of the power dissipated through the eddy currents are given by the

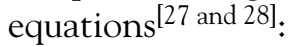

$$
\begin{aligned}
& \underline{\mathrm{J}}=\frac{\mathrm{d} \underline{\mathrm{H}}}{\mathrm{dr}} \\
& \mathrm{p}=\frac{\mathrm{J}^{2}}{\sigma}
\end{aligned}
$$

\subsubsection{Defining the initial conditions and the boundary conditions}

In modeling with FDM, the boundary of analyzed domain is the surface of steel piece, characterized by $r=d_{2} / 2$.

For the electromagnetic field the boundary condition is of Dirichlet type:

$$
\mathrm{H}=\mathrm{H}_{\text {ext }} \text {, at } \mathrm{r}=\mathrm{d}_{2} / 2, \mathrm{t}>0
$$

and for the thermal field the boundary condition is of Robin type:

$$
\lambda \frac{\mathrm{dT}}{\mathrm{dr}}+\alpha\left(\mathrm{T}-\mathrm{T}_{\mathrm{a}}\right)=0, \text { at } \mathrm{r}=\mathrm{d}_{2} / 2, \mathrm{t}>0
$$

in the hypothesis of some thermal losses by convection on the surface of the steel piece (the thermal losses through the furnace cover and hearth are neglected).

In the equations (6), (7) $\mathrm{H}_{\text {ext }}$ represents the intensity of magnetic field on the surface of the steel piece, $T_{a}$ represents the air temperature in the neighborhood of the steel piece and $\alpha\left[\mathrm{W} / \mathrm{m}^{2}{ }^{\circ} \mathrm{C}\right]$ is its heat transfer coefficient.

\subsubsection{Computation domain discretization}

Because the steel piece presents an axial symmetry, and assuming negligible the ending effect and the thermal losses through the furnace cover and hearth, the discretization of computation domain can be done by concentric cylindrical surfaces.

Thus a 1-D model is obtained (Fig. 3). This version is the most simple and economic from the viewpoint of CPU time.

In the case of induction heating, the phenomena are determinative on a depth that is equally with that 


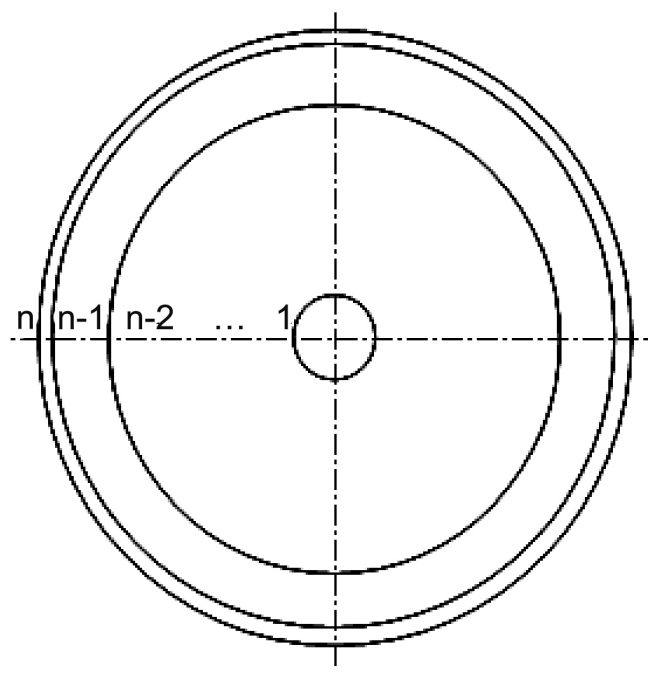

Figure 3. Mesh of the computation domain (piece).

Figura 3. Discretización del dominio de cálculo (pieza).

one for the electromagnetic field penetration. In these conditions, it is necessary to consider at least 2-3 intervals of discretization on the initial penetration depth. On a depth higher than the penetration depth, a mesh can be achieved by increasing the step in geometric progression.

For these reasons, in spatial discretization a mesh with variable step has been used, which leads to more accurate results than the discretization with constant step. Thus, a finer discretization at the surface of piece has been achieved, and in the rest of the domain a higher step of the mesh was used.

\subsubsection{The model in finite differences of the coupled electromagnetic and thermal fields}

The model into the finite differences of the coupled electromagnetic and thermal fields is given by the relations (8), (9).

$$
\begin{aligned}
& \underline{H}_{i-1}^{k, q}\left[\frac{r_{i}+r_{i-1}}{r_{i}\left(r_{i+1}-r_{i-1}\right)\left(r_{i}-r_{i-1}\right)}+\frac{\sigma_{i+1}^{k-1}-\sigma_{i-1}^{k-1}}{\sigma_{i}^{k-1}\left(r_{i+1}-r_{i-1}\right)^{2}}\right] \\
& -\underline{H}_{i}^{k, q}\left[\frac{2}{\left(r_{i+1}-r_{i}\right)\left(r_{i}-r_{i-1}\right)}+j \omega \sigma_{i}^{k-1} \mu_{i}^{k, q-1}+\frac{\sigma_{i}^{k-1} \mid\left(\mu_{i}^{k, q-1}-\mu_{i}^{k-1}\right)}{t_{k}-t_{k-1}}\right] \\
& +\underline{H}_{i+1}^{k, q}\left[\frac{r_{i+1}+r_{i}}{r_{i}\left(r_{i+1}-r_{i-1}\right)\left(r_{i+1}-r_{i}\right)}-\frac{\sigma_{i+1}^{k-1}-\sigma_{i-1}^{k-1}}{\sigma_{i}^{k-1}\left(r_{i+1}-r_{i-1}\right)^{2}}\right]=0
\end{aligned}
$$

$$
\begin{aligned}
& T_{i-1}^{k}\left[\frac{r_{i}+r_{i-1}}{\left.r_{i}\left(r_{i+1}-r_{i-1}\right) \mid r_{i}-r_{i-1}\right)}-\frac{\lambda_{i+1}^{k-1}-\lambda_{i-1}^{k-1}}{\lambda_{i}^{k-1}\left(r_{i+1}-r_{i-1}\right)^{2}}\right]-T_{i}^{k}\left[\frac{2}{\left(r_{i+1}-r_{i}\right)\left(r_{i}-r_{i-1}\right)}\right] \\
& -T_{i}^{k}\left[\frac{\gamma c}{\lambda_{i}^{k-1}\left(t_{k}-t_{k-1}\right)}\right]+T_{i+1}^{k}\left[\frac{r_{i+1}+r_{i}}{r_{i}\left(r_{i+1}-r_{i-1}\right)\left(r_{i+1}-r_{i}\right)}+\frac{\lambda_{i+1}^{k-1}-\lambda_{i-1}^{k-1}}{\lambda_{i}^{k-1}\left(r_{i+1}-r_{i-1}\right)^{2}}\right] \\
& =-\frac{p_{i}^{k-1}}{\lambda_{i}^{k-1}}-\frac{\gamma c T_{i}^{k-1}}{\lambda_{i}^{k-1}\left(t_{k}-t_{k-1}\right)}
\end{aligned}
$$

The boundary conditions (for $\left.r_{n}=d_{2} / 2\right)$ become:

$$
\begin{aligned}
& \underline{H}_{n}^{k}=\underline{H}_{\text {ext }}, \\
& \frac{\lambda_{n}^{k-1}\left(T_{n}^{k}-T_{n-1}^{k}\right)}{r_{n}-r_{n-1}}+\alpha\left(T_{n}^{k}-T_{a}\right)=0
\end{aligned}
$$

The density of the eddy currents induced within the steel piece and the volume density of the active power dissipated through the eddy currents are given by the equations (11) and (12).

$$
\begin{gathered}
\underline{J}_{i}^{k}=\frac{H_{i+1}^{k}-\underline{H}_{i-1}^{k}}{r_{i+1}-r_{i-1}} \\
p_{i}^{k}=\frac{1}{\sigma_{i}^{k-1}}\left|\frac{\underline{H}_{i+1}^{k}-\underline{H}_{i-1}^{k}}{r_{i+1}-r_{i-1}}\right|^{2}
\end{gathered}
$$

For obtaing the relations (8)-(12) the centered difference formula is used, renouncing at the remainder terms.

In (8) $-(12), i=1,2,3, \ldots, \mathrm{n}-1$ (the first node of the mesh corresponds to radius $r_{0}=0$, and the last node of the discretization mesh, $n$, corresponds to $\left.r_{n}=d_{2} / 2\right)$.

The index $k$ defines the time moment. The index $q$ defines the number of iterations (at the same time moment $t_{k}$ ) needed to compute the intensity of magnetic field (because of the magnetic non-linearity of the processed material).

The distribution of magnetic field in the steel piece at iteration $q$ is computed depending upon the magnetic permeability values $\mu_{i}^{k, q-1}$ at the previous iteration $q-1$ (within the same time step $t_{k}$ ) and depending upon the magnetic permeability values $\mu_{i}^{k-1}$ at the previous time step.

The iterative process will be led as follows: 
TECHNOLOGICAL PRACTICABILITY OF THE NUMERICAL MODELING OF INDUCTION HEATING PROCESS IN STEEL PIECES LA UTILIDAD TECNOLÓGICA DEL MODELADO NUMÉRICO EN EL CALENTAMIENTO POR INDUCCIÓN DE LAS PIEZAS DE ACERO

- the thermal field within the steel piece is considered the initial one $\left(T_{i n}\right)$;

- the initial value of the relative magnetic permeability is the same in all points inside the steel piece and is estimated from the previous calculations;

- the system (8) is solved, resulting a first solution of the magnetic field from the steel piece $\underline{H}_{i}^{k, 1}$;

- with the new values of the magnetic permeability $\mu\left(H_{i}^{k, 1}, T_{i n}\right)$ (obtained from the dependences $\mu(H, T)$ the system (8) is solved again, obtaining a solution $\underline{H}_{i}^{k, 2}$; this solution is compared with the one resulted at the previous iteration $\left(\underline{H}_{i}^{k, 1}\right)$;

- the iterations continue until satisfying of an imposed error criterion $\left(\varepsilon_{H}\right)$ :

$$
\left|H_{i}^{k, q}-H_{i}^{k, q-1}\right|<\varepsilon_{H}
$$

In any stage of the study, the computation of the magnetic field (in steel piece) is initialized with the values of the magnetic permeability computed at the last iteration within the previous time step.

The number of $q$ iterations depends on reaching the imposed error $\hat{A}_{H}$ for the computation of the magnetic field intensity at each time moment.

\subsubsection{The results of numerical modeling using FDM}

For the computing of the electromagnetic and thermal fields within the steel piece, a $\mathrm{C}++$ program, based on (8) - (13) has been developed.

Figure $4(a, b, c)$ shows the results of the numerical modeling regarding the density of the eddy currents, the volume density of the active power and temperature (depending upon the radius $r$ ), at the various moments of the heating process. Figure 4 (d) shows the time variation of temperature in the same radial coordinate.

\subsection{The numerical modeling of the electromagnetic and thermal fields within a steel piece using FEM}

The FEM modeling was done using the commercial code FLUX 2D ${ }^{[29]}$; the modeling did not include the melting and heating at the liquid stage of the processed material.

\subsubsection{The computation domain and geo- metrical discretization of this one}

In the modeling made by FLUX 2D, the computation domain (Fig. 5) has been reduced to a quarter of the initial physical model (Fig. 1), because of the axisymmetry and the similar conditions of heat transfer at the upper and lower area of the furnace (due to its cover and hearth). In this way, the initial problem (3-D) can be analyzed in a more simplified version (2-D).

In the computation domain the following surfaces have been defined: $\square$ air; $\square$ inductor; $\square$ crucible; indus; cover; asbestos, infinity region, and two shell regions: convsam, convazb, which are modeling the cover-air and crucible-air thermal convection.

The adequate materials have been assigned to the regions we defined previously, together with electric, magnetic and thermal properties.

The program FLUX 2D allows to extend the domain of study up to infinity by an artificially created region (infinity region) [29].

For induction heating problems, at least two mesh elements should make up the thickness of the skin depth (of electromagnetic field) ${ }^{[29]}$. For this reason a fine mesh was created in the region of interest for the electromagnetic field, and more coarsely towards the symmetry axis, respectively towards the other boundaries of the computation domain.

The mesh of the computation domain is shown in figure 5. A detail regarding the meshing of steel piece is shown in figure 6 .

\subsubsection{Defining the boundary conditions}

In the coupled problems (magneto-thermal) the solving of the electromagnetic problem is imposed over the thermal one. In the interior of a finite element FLUX 2D uses a parabolic approximation for the variable of the field ${ }^{[29]}$.

For the analysis of electromagnetic field, the boundary conditions are established as follows (Fig. 5):

- on the symmetry axis and on the boundary parallel to a flux density line, the boundary conditions are of Dirichlet type $(A=0$, where A represents the vector potential, [Wb/m]);

- if the boundary is normal to the flux density lines (i.e. on the median plane, characterized by $z=0)$, the boundary condition is of Neumann type $(\partial A / \partial n=0)$.

For thermal problem the computation domain can be reduced to that one presented in figure 7 . The 


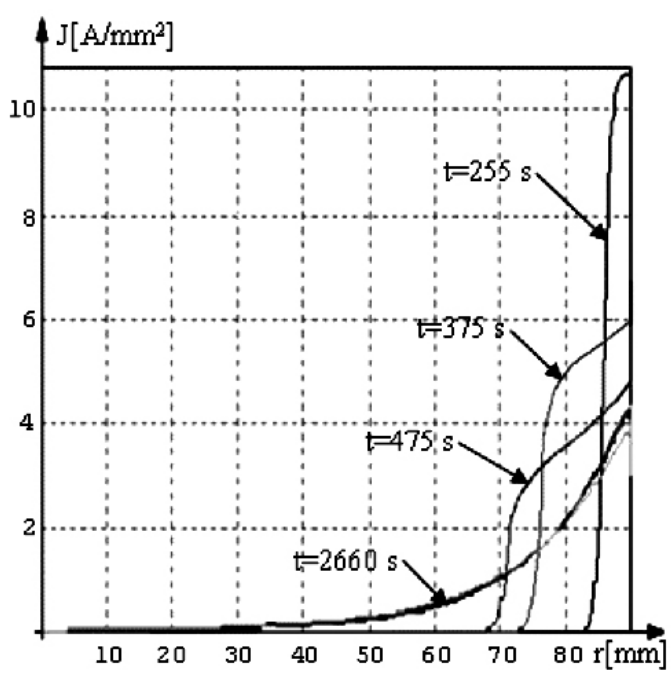

a)

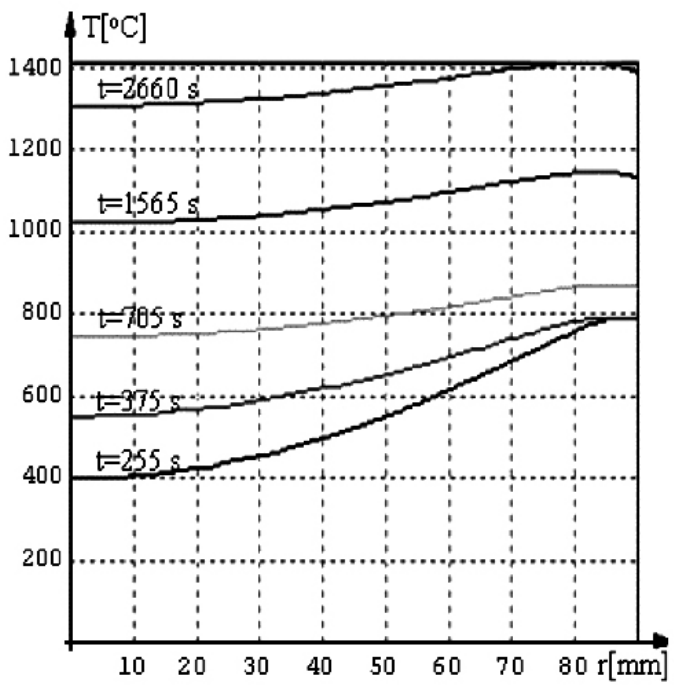

c)

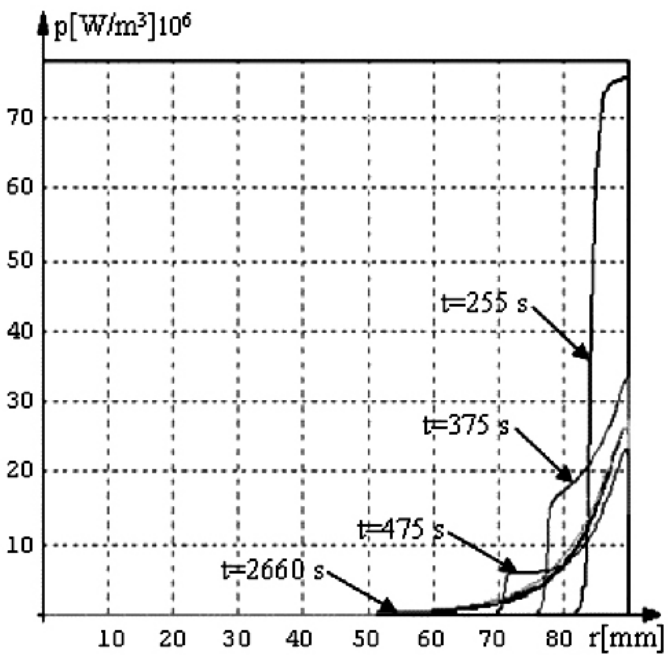

b)

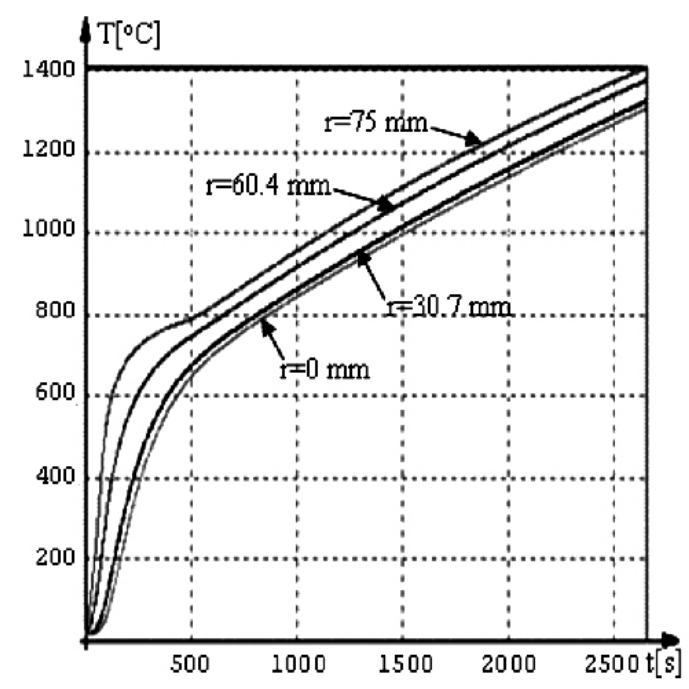

d)

Figure 4. The results of numerical modeling using FDM: a) The magnitude of the current density; b) Power density; c) The distribution of temperature in the processed material, at various moments; d) The time variation of the temperatures.

Figura 4. Resultados del modelado numérico usando FDM: a) Amplitud de la densidad de corriente; b) Densidad de potencia; c) Distribución de la temperatura en el material procesado, en distintos momentos; d) Variación en tiempo de la temperatura.

eddy currents induced in the steel piece represent the sources for the thermal field.

The boundary conditions for thermal problem are of type:

- Neumann, homogeneous, on the symmetry axes: $\frac{\partial T}{\partial A}=0$;

- Robin, on the surfaces where thermal convection exist (cover-air and asbestos-air): $-\lambda \frac{\partial T}{\partial n}=\alpha\left(T_{i n t}-T_{a}\right)$.

\subsubsection{The results of numerical modeling using FEM}

Figure $8 \mathrm{a}$ ) and b) shows the results of the numerical modeling regarding the density of the eddy currents and the volume density of the active power, for the various moments of the heating process.

The heating of the steel piece can be observed on the temperature charts obtained by FLUX 2D.

Figure 9 a) and b) presents two moments of the 
TECHNOLOGICAL PRACTICABILITY OF THE NUMERICAL MODELING OF INDUCTION HEATING PROCESS IN STEEL PIECES LA UTILIDAD TECNOLÓGICA DEL MODELADO NUMÉRICO EN EL CALENTAMIENTO POR INDUCCIÓN DE LAS PIEZAS DE ACERO

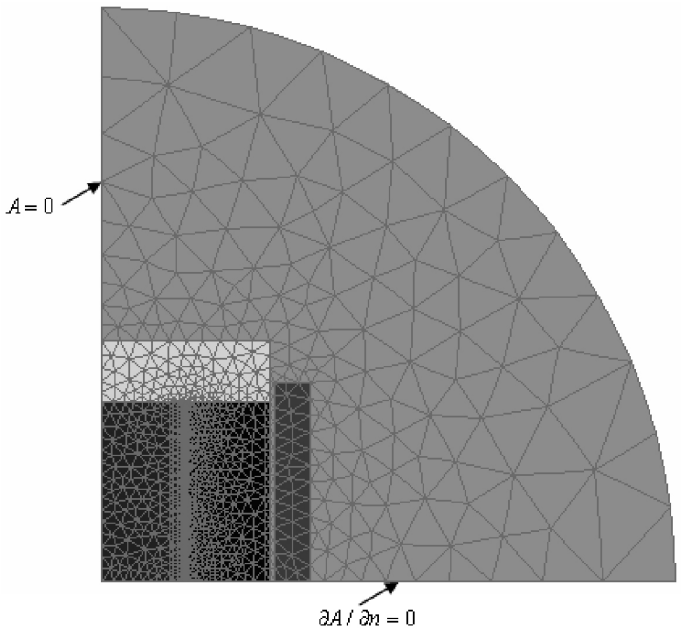

Figure 5. Mesh of the computation domain and the boundary conditions for electromagnetic field.

Figura 5. Discreción del dominio de cálculo y las condiciones de frontera para el campo electromagnético.

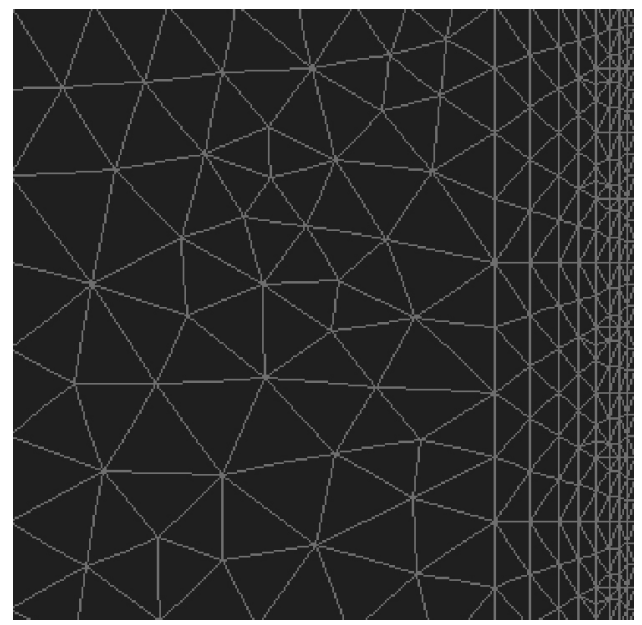

Figure 6. Mesh of the indus (detail).

Figura 6. Discreción del inducido (detalle).

heating process: $t=255 \mathrm{~s}$ (after $255 \mathrm{~s}$ from the beginning of the heating) and $t=2665 \mathrm{~s}$ (the end of the heating process).

The analysis of the numerical modelings results (FDM and FEM) shows that in the first heating moments, the electromagnetic field is concentrated on the surface of the processed material (Fig. $4 \mathrm{a}$ ) and b) and Fig. $8(\mathrm{a}, \mathrm{b})$, the time moment $t=255 \mathrm{~s})$. The heating of steel piece is done from exterior towards interior (Fig. 9 (a)).

In figure 4 a) and b) and figure 8 a) and b) are

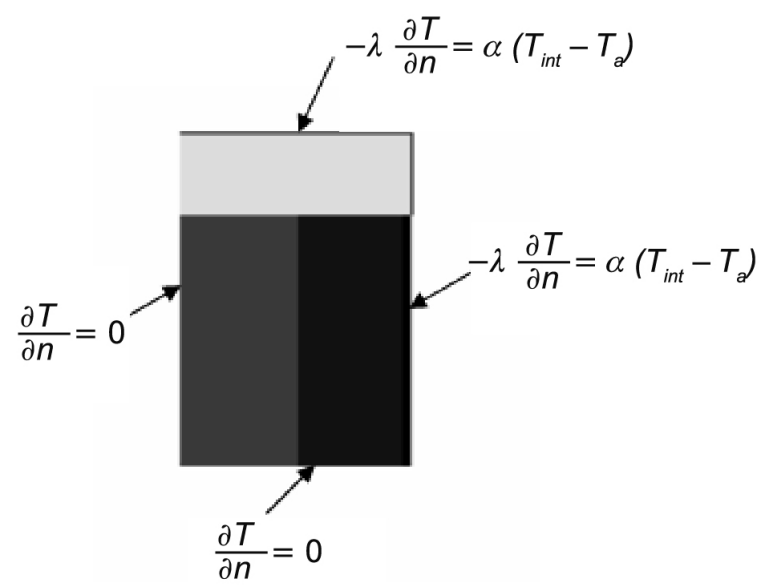

Figure 7. Computation domain for the thermal problem and the boundary conditions.

Figura 7. Dominio de cálculo para el problema térmico y las condiciones de frontera.

caught two moments $(t=375 \mathrm{~s}$ and $t=475 \mathrm{~s})$ of the ,intermediate state”.

The temperature increases very much (and nonlinearly) in the first $500 \mathrm{~s}$ from the beginning of the heating process (Fig. $4 \mathrm{~d}$ )), because in this period of time the processed material has ferromagnetic properties in the greatest part of its volume; after reaching the Curie temperature in the entire volume of steel piece, the time-variation of temperature becomes linear (the steel being paramagnetic in this situation).

Because the electromagnetic field penetrates into a relatively thin layer from the surface (Fig. 4 a) and b)), the internal part of steel piece is heating up only by thermal conduction in the first stage. This fact is caught in figure $4(\mathrm{~d})$, for $r=0$ and $r=30.7 \mathrm{~mm}$.

At the end of the heating process the temperature distribution is relatively homogeneous in the entire volume of steel piece (Fig. 4 c) and Fig. 9 (b)).

\section{EXPERIMENTAL VALIDATIONS}

Figure $10 \mathrm{a}), \mathrm{b}), \mathrm{c}$ ) and d) shows the time variation of the temperatures, as resulting from the numerical simulation, and of the temperatures measured at various cylindrical coordinates.

\section{CONCLUSIONS}

Modeling of the inductive heating of cylindrical steel piece was achieved with two numerical methods, FDM and FEM. 
Current density Magni tude straicht seqment $R=0.1 \quad Z=37, R=90.1 \quad Z=37$

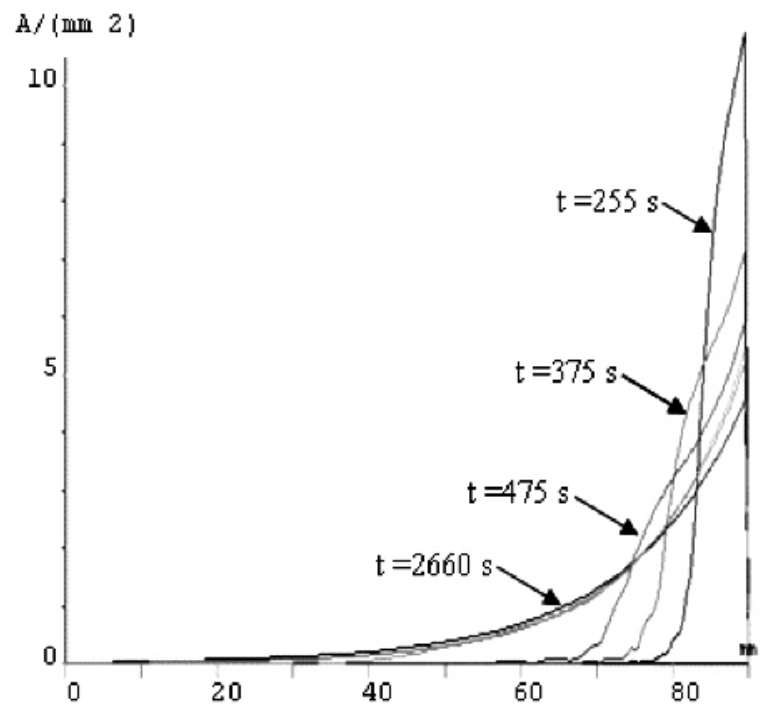

a)
Power density

straight seqment $R=0.1 \quad Z=37, R=90.1 \quad Z=37$

W/ (cubic m) E6

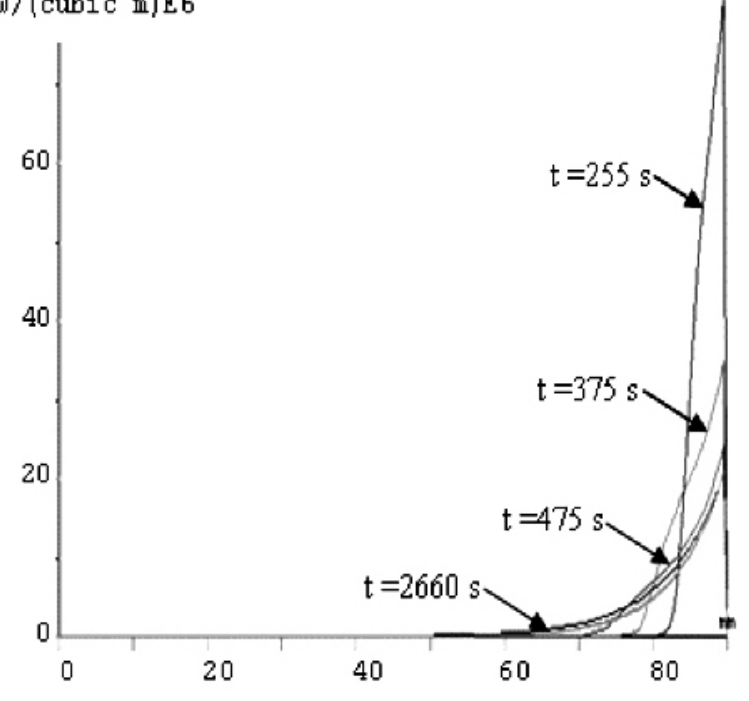

b)

Figure 8. The results of numerical modeling using FEM: a) The magnitude of the current density; b) Power density.

Figura 8. Resultados del modelado numérico usando FEM: a) Amplitud de la densidad de corriente; b) Densidad de potencia.

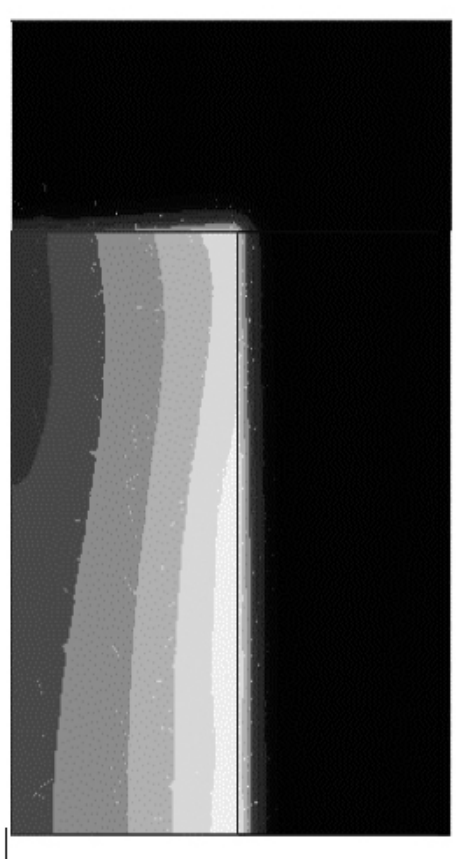

a)

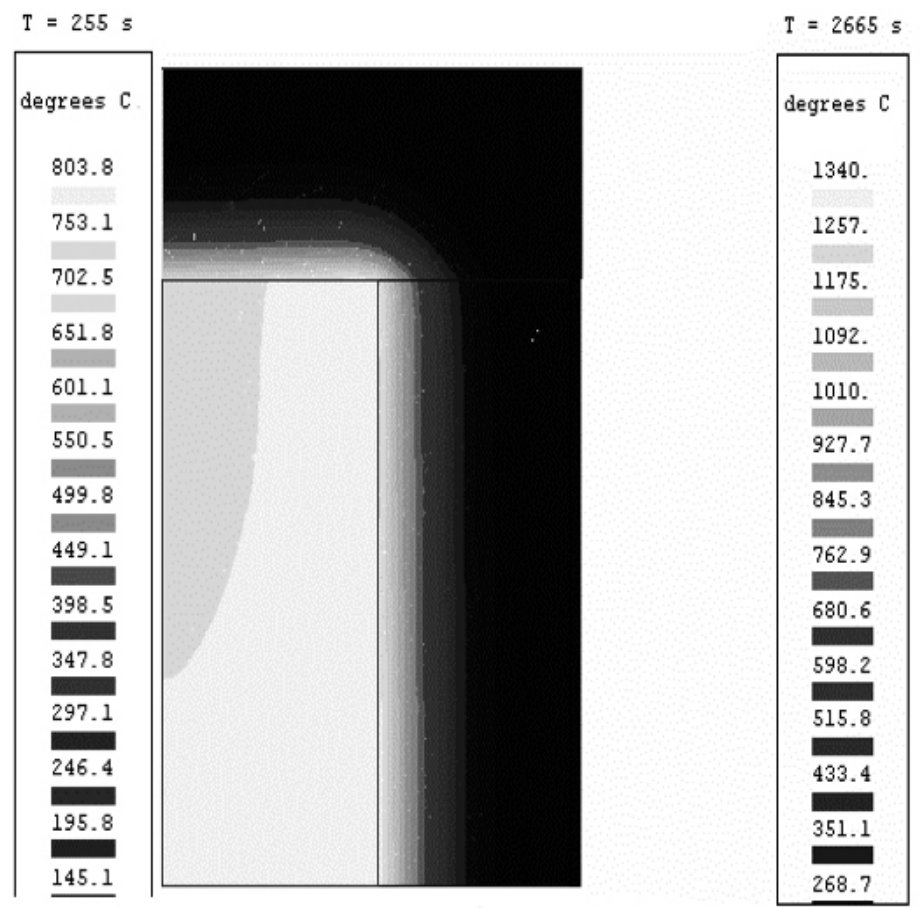

b)

Figure 9. Temperature charts of the steel piece: a) $t=255 \mathrm{~s} ; \mathrm{b}) \mathrm{t}=2665 \mathrm{~s}$.

Figura 9. Mapas de temperatura de la pieza de acero: a) $t=255 \mathrm{~s}$; b) $t=2665 \mathrm{~s}$. 
TECHNOLOGICAL PRACTICABILITY OF THE NUMERICAL MODELING OF INDUCTION HEATING PROCESS IN STEEL PIECES LA UTILIDAD TECNOLÓGICA DEL MODELADO NUMÉRICO EN EL CALENTAMIENTO POR INDUCCIÓN DE LAS PIEZAS DE ACERO

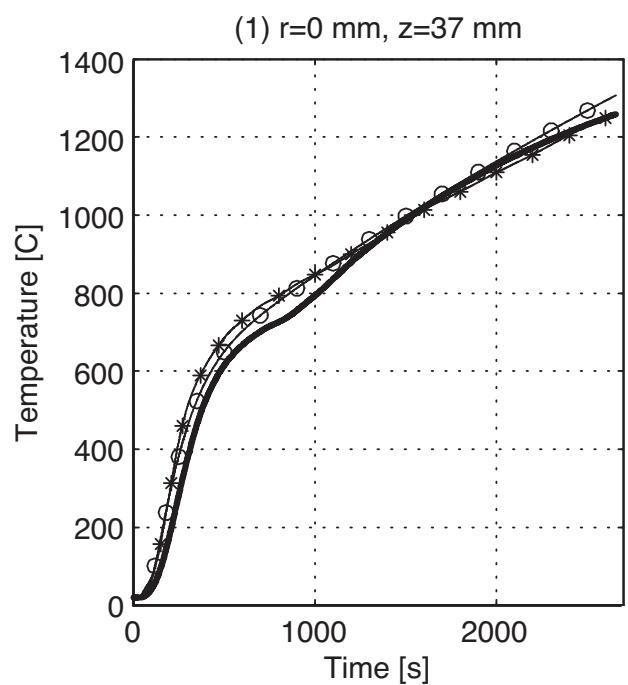

a)

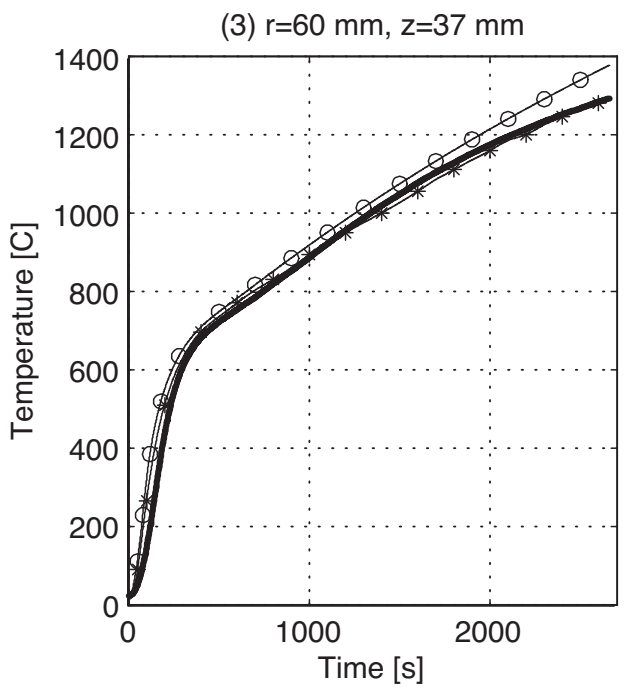

c)

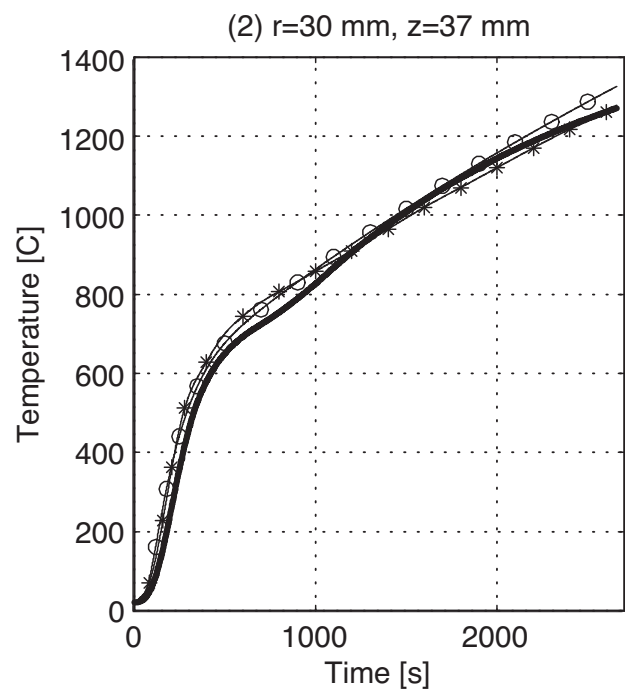

b)

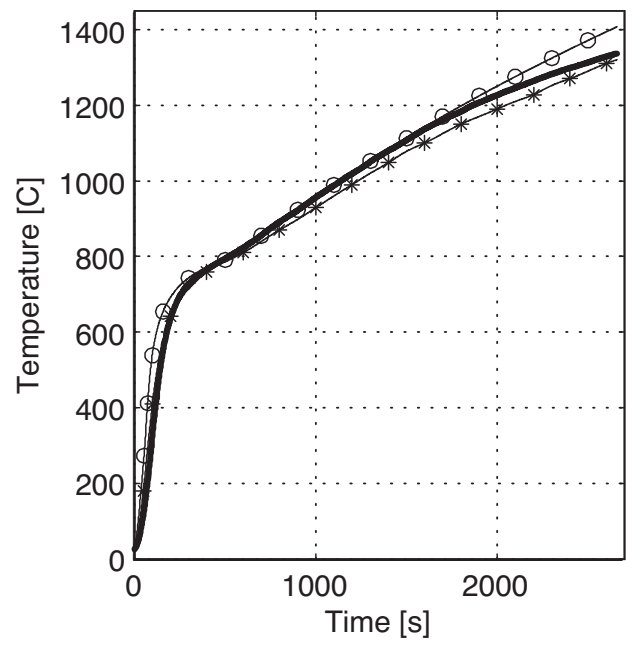

d)

Figure 10. The time variation of the temperatures resulted from numerical simulation and of the measured temperatures: experimental values; o FDM simulation; . FEM simulation a) $r=0 \mathrm{~mm}, z=$ $37 \mathrm{~mm}$; b) $r=30 \mathrm{~mm}, z=37 \mathrm{~mm}$; ) $r=60 \mathrm{~mm}, z=37 \mathrm{~mm}$; d) $r=75 \mathrm{~mm}, z=37 \mathrm{~mm}$.

Figura 10. Variación en tiempo de las temperaturas resultadas por numérica y de las temperaturas medidas: temperaturas medidas; o FDM simulación ; FEM simulación a) $r=0 \mathrm{~mm}, z=37 \mathrm{~mm}$; b) $r=30$ $\mathrm{mm}, z=37 \mathrm{~mm}$; c) $r=60 \mathrm{~mm}, z=37 \mathrm{~mm}$; d) $r=75 \mathrm{~mm}, z=37 \mathrm{~mm}$.

Based on the FDM modeling we developed a simulation program which uses a $1-\mathrm{D}$ model, and in FEM modeling we used the FLUX 2D commercial code.

FDM modeling offers the following advantages: the numerical transposition of the equations that describe the electromagnetic and thermal fields from the steel piece are achieved easily; the simulation program has a simple structure; the memory requirement is reduced; the $\mathrm{CPU}$ time is low.

The FDM modeling leads to a CPU time with about one magnitude order smaller than the FEM modeling.

The convergence is ensured by imposing a sufficiently small error in the quantities of coupled fields computation (electromagnetic-thermal), and 
by correlating the time step with the temperature reached inside the steel piece.

The analysis of the two numerical modelings shows a good concordance between the diverse results. Thus, for $z=37 \mathrm{~mm}$, the relative differences do not exceed $15 \%$ in the case of active power density and density of the eddy currents induced into the steel piece, respectively $7 \%$ in the case of temperature. This shows that the hypotheses admitted in FDM modeling are acceptable for the studied case.

Also, a good concordance between the simulated temperatures and measured temperatures from the steel piece is found.

The difference between the simulated temperatures and measured values is at the most $11 \%$ (FEM modeling) and respectively $14 \%$ (FDM modeling). These differences can be, on one side, due to the fact that the very complex and strongly coupled phenomena involved in the inductive heating of the steel piece (within the modelings we could not take into account all the physical aspects); on the other side, the possible measuring errors of the temperatures because of the thermocouples must be considered.

The differences between the simulated and measured values of temperatures are more pronounced in the intermediate state, when the steel losses its ferromagnetic properties and become paramagnetic.

Both modelings being experimentally validated, they can be used for the designing of some inductive heating equipments.

The program written in $\mathrm{C}++$ can be used in the first stage of designing due to the short CPU time. In this stage the inductor parameters (geometrical dimensions, electrical current, supplying voltage, power) and the heating time can be estimated; also, a study of the influence regarding the different factors upon the heating process (frequency, supplying voltage), in the view of its optimization, can be realized.

The FLUX 2D program can be used in the optimization stage, because it allows a more detailed analysis of the phenomena.

The optimization of the induction heating process presumes a very precise and rapid control of the steel piece temperature, in such way as to satisfy the technological requirements in the conditions of a minimal heating time and a minimal power supply.

The numerical modeling of the induction heating process allows the determination of the temperature at any point inside the steel piece, if the temperature can be measured on its surface. This information (regarding the temperature on the surface of the piece) is essential for the automatic control of the process, in conformity with the pre-established technological requirements.
The results of the numerical modeling allow for the achievement of an efficient numerical control system for the induction heating of steel pieces.

\section{REFERENCES}

[1] T. Leuca, Electromagnetic field and thermal coupled field. Eddy currents (in Romanian), Editura Mediamira, Cluj-Napoca, Romania, 1996, pp. 16-23 and 78-81.

[2] I. Sora, N. Golovanov, L. Cantemir, N. Mogoreanu, M. Chindris, M. Ungureanu, V. Fireteanu, D. Ioachim, Gh. Floriganta and R. Popa, Electrothermal conversion and electrotechnologies, vol. 1 (in Romanian), EdituraTehnica, Bucharest, Romania, 1997, pp. 274-298.

[3] Y. Pleshivtseva, Int. J. Mater. Prod. Technol. 29 (2007) 137-148.

[4] A. Bermúdez, D. Gómez, M. C. Muñiz and P. Salgado, Int. J. Numer. Meth. Eng. 71 (2007) 879-882.

[5] A. Bermúdez, D. Gómez, M. Muñiz and P. Salgado, Adv. Comput. Math. 26 (2007) 39-62.

[6] F. Bay, V. Labbé and Y. Favennec, Int. J. Mater. Prod. Technol. 29 (2007) 52-69.

[7] F. Bay, V. Labbé, Y. Favennec and J. L. Chenot, Int. J. Numer. Meth. Eng. 58 (2003) 839-867.

[8] K. Kurek and D. M. Dolega, Int. J. Mater. Prod. Technol. 29 (2007) 84-102.

[9] J. Grum, Int. J. Mater. Prod. Technol. 29 (2007) 211-227.

[10] R. Hiptmair and O. Sterz, Int. J. Numer. Model. 18 (2005) 1-21.

[11] A. Masserey, J. Rappaz, R. Rozsnyo, M. Swierkosz, J. Comput. Phys., 205 (2005) 48-71.

[12] V. Rudnev, Int. J. Mater. Prod. Technol. 29 (2007) 43-51.

[13] N. Mole and B. Stok, 8th Seminar of the International Federation for Heat Treatment and Surface Engineering - IFHTSE2001 Dubrovnik, Croatia, 2001.

[14] A. Alonso Rodriguez, R. Hiptmair and A. Valli, J. Numer. Anal. 24 (2004) 255-271.

[15] V. Fireteanu and T. Tudorache, Int. J. Comput Math. Electr. Electron. Eng. 22 (2003) 68-78.[

16] Y. Favennec, V. Labbé and F. Bay, J. Comput. Phys. 187 (2003) 68-94.

[17] P. D. Barba, A. Savini, F. Dughiero and S. Lupi, Int. J. Comput. Math. Electr. Electron. Eng. 22 (2003) 111-122.

[18] P. D. Barba, B. Forghani and D. A. Lowther, COMPEL: Int. J. Comput Math. Electr. Electron. Eng. 24 (2005) 271-280. 
TECHNOLOGICAL PRACTICABILITY OF THE NUMERICAL MODELING OF INDUCTION HEATING PROCESS IN STEEL PIECES LA UTILIDAD TECNOLÓGICA DEL MODELADO NUMÉRICO EN EL CALENTAMIENTO POR INDUCCIÓN DE LAS PIEZAS DE ACERO

[19] O. Bodart, A. Boureau and R. Touzani, Appl. Math. Model. 25 (2001) 697-712.

[20] B. Drobenko, O. Hachkevych and T. Kournyts'kyi, Int. J. Heat Mass Transfer. 50 (2007) 616-624.

[21] J. Grum, Int. J. Mater. Prod. Technol. 29 (2007) 200-210.

[22] A. Masserey, R. Rozsnyo, J. Rappaz, R. Touzani, Int. J. Appl. Electrom. Mech. 19 (2004) 51-56.

[23] J. Zgraja, Int. J. Comput. Math. Electr. Electron. Eng.. 24 (2005) 305-313.

[24] C. Parietti and J. Rappaz, Math. Mod. Meth. Appl. Sci. 9 (1999) 1333-1350.
[25] *** Flux Magazine, Cedrat, no 51, June 2006, pp. 8-9.

[26] http://www.arc.ro Products catalogue, ARC Brasov, 2002.

[27] A. Iagar, PhD Thesis, Faculty of Electrical Engineering, Politehnica University of Timisoara, 2005.

[28] I. Sora, A. Iagar, N. Rusu, D. Radu and C. Panoiu, Rev. Roum. Sci. Technol. Electrotechn. Energ. 2 (2006) 169-182.

[29] http://www.cedrat.com FLUX 2D Version 7.40 User's guide, Cedrat, 1999. 